\title{
The design of the lamp wireless energy-saving control system
}

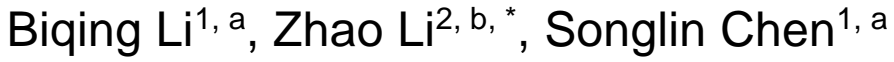 \\ ${ }^{1}$ College of Mechanical and Electronic Engineering, Hezhou University, Hezhou Guangxi 542899, \\ China; \\ ${ }^{2}$ Management Engineering Department, Guangxi vocational and technical college of communications, \\ Liuzhou Guangxi 545000, China; \\ ajanliful@163.com, b229292710@qq.com
}

\section{Keywords: 315MHZ STC89C52, DS1302, Pyroelectric infrared human body induction}

\begin{abstract}
This design is a system which makes use of wireless technology to control circuit. The main engine of the system is composed by STC89C52SCM, key, DS1302 (clock chip), 315Mtransmitter module and Light detection circuit. The slave is composed by $315 \mathrm{M}$ wireless module and pyroelectric infrared human body induction module. The system constitutes a complete signal processing circuit through the remote wireless communication network, the single-chip microcomputer control center and LED lamp control terminal. It can not only save energy and money, but also can improve target localization accuracy and reduce management costs, so that offer facilities for people's work and life. After debugging, this design has reached all the expected requirements.
\end{abstract}

\section{Introduction}

The lighting of traditional urban road is a waste of electricity which is generally closed during the day and open at night. Maintenance and management are manual operation, workload and difficulty, and the cost is very high.With the rapid development of city urbanization, city public infrastructure construction are constantly adding mass, city road is also increasing, the number of streetlights are increasing every year, and the traditional management of city road lighting has been unable to meet the basic requirement of the social development and the people, in order to protect the city people's normal life, we need to put forward control system, realize the city lights of green lighting, ensure adequate lighting, convenient for people's life and work, but also can save energy and reduce environmental pollution.

The design of wireless network node based on 315M radio frequency module can combine with LED light source to form an efficient street lamp system. The distance of the wireless transceiver system can reach nearly a thousand meters, which it makes up for the shortcomings of short distance wireless control to some extent. The utility model has the advantages of the communication address, the communication baud rate and the $315 \mathrm{M}$ wireless address, and the utility model has the advantages of simple interface, strong anti-interference ability, small transmitting power, multiple nodes and so on. It is widely used by its hardware cost can be controlled effectively.

\section{Hardware design}

The wireless energy saving control system designed in this paper is divided into six parts. The block diagram of the system is shown in figure 1.On the one hand, the system adopts $315 \mathrm{~m}$ wireless transmitter module to collect code modulation. It will send the data to the transmitting module transmitted by STC89C52 which deal with the main information at the receiving end of 315m super regenerative receiver module receives the signal and demodulates the data, and finally displayed by a LCD1602 liquid crystal. On the other hand, the use of photosensitive resistor to detect the environment, the street lamp will automatically light up, on the contrary is not bright when the infrared sensor to the infrared signal. The use of buttons to set the timing, delay, set the lighting time of street lamp and delay time, using LCD16024 as a display device, for the corresponding display.The design of wireless 
control is mainly composed of SCM and transceiver module by the network generated.It will send control commands to the street lamp and control the street lights of the LED. The module realizes the energy saving by controlling the LED of the outside environment. The control module is composed of a single chip microcomputer and a relay. The central processor of the system uses STC89C52 as the microprocessor, and uses the closing and disconnecting of the relay to control the switch of the LED street lamp.In the design, it can be used to isolate the $315 \mathrm{M}$ wireless receiving module and the infrared induction module, so as to avoid mutual interference signal.

\section{Light detection circuit}

Designed to use photometric components as photosensitive devices, the sensitivity is very high.The light detection adjusts the sensitivity by the potentiometer to adjust the sensitivity. NPN transistor conduction or cut-off state by the R2 and R4 partial pressure to control. The resistance of the photosensitive resistor $\mathrm{R}$ is affected by the light intensity. When there is light, the varistor divides the voltage between the base of the transistor and the base electrode, and the transistor turns on. When there is no light, the photosensitive resistor at this time becomes much larger than the resistance of the varistor, the voltage through the varistor is almost negligible, and the voltage between the transistor $\mathrm{B}$ pole and the E pole is less than $0.7 \mathrm{~V}$ and cut off. The light detection circuit is mainly collected on the light, after the processor processing, the information obtained to return to the system control center, intelligent control system by judging the strength of light, according to the current environment, the decision to make the light off, Thus saving energy.

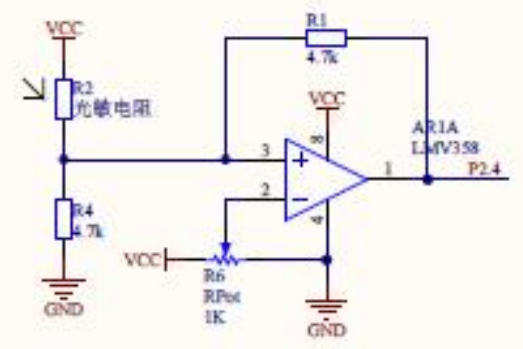

\section{Pyroelectric human body infrared sensor module}

The design of the pyroelectric infrared sensor whether there is an object passing through, when the induction of infrared radiation to the object, the LED lights automatically lit, on the contrary is not bright, so as to achieve the effect of saving electricity. The LHI778 probe in the module can be used to transmit the infrared signal emitted by the human body through the infrared technology, the sensitivity is very high, the reliability is very strong, the power consumption is small, and the utility model works in the ultra low voltage mode.

Repeatable trigger mode is a flexible control mode, according to the environmental needs to do the corresponding operation, high level output in the induction, during this period, if the induction range in human activities, its output will always maintain a high level. The adopt of design is repetitive trigger mode control, not only can save energy, but also for the convenience of people who travel at night.

\section{Conclusion}

The paper combined with single chip technology, human induction technology and wireless communication technology, a short distance wireless intelligent control LED street lamp which can save energy is designed.According to the ambient light intensity the system can automatically adjust the lighting state, it can be realized within a certain region of perception of the human body, and through the wireless communication signal and transmits the data to the host.The controller can 
independently control the lighting time of each street lamp through the key setting. The system has the advantages of high cost performance, low hardware cost and maintenance cost, low power consumption and environmental protection, which is in line with the requirements of the society for green economy and energy saving.

\section{Acknowledgements}

This work is supported the following fund: 2016 The project of improving the basic ability of young teachers in Colleges and universities in Guangxi: "Design and development of electronic commerce platform of agricultural products based on Semantic Technology" (No,KY2016YB455).2015 college students' innovative training program: "Research on the application of value added travel experience in the mobile terminal of the 'ethnic custom travel' in Guangxi" (No 201511838070);\&\& "The design and development HeYuanTong Campus Mobile Phone APP based on Android" (No 201511838034). Project of scientific research and technology development project of Hezhou: "Design and implementation of agricultural products e-commerce platform based on Semantic Technology" (No, Hekeneng 1506006).

\section{References}

[1] B.Q LI, Y.F LING, H.Y ZHANG, and S.Y ZHENG: The Design and Realization of Cherry Tomato Harvesting Robot Based on IOT. International Journal of Online Engineering, 12(12), 23, (2016).

[2] B.Q LI, W.L GUAN, S.Y Zheng, X.G Yue: OPTIMISATION DESIGN OF CORN PRECISION SEEDER BASED ON MULTI-ROUTE AND MULTI-CHANNEL CONTROL. JOURNAL OF THE BALKAN TRIBOLOGICAL ASSOCIATION, 21(4A), 1215, (2015).

[3] Li Biqing, Zhu Qiang, Chen Ke Qing, Chen Ke Yin. Design of weed automatic recognition weeding robot based on embedded Web and ZigBee gateway. [J] Agricultural Mechanization Research. 2017.1 (1)

[4] B.Q Li, et al, Intelligent Control Management System and Its Application, in: PROCEEDINGS OF THE 2016 INTERNATIONAL CONFERENCE ON ECONOMICS AND MANAGEMENT INNOVATIONS, Wuhan, China, 2016, PP.68-71.

[5] B.Q Li, et al, Design and Implementation of Tanks War Game Based on the Android Platform, in: PROCEEDINGS OF THE 2016 2ND WROKSHOP ON ADVANCED RESEARCH AND TECHNOLOGY IN INDUSTRY APPLICATIONS, Dalian, China, 2016, PP.963-966.

[6] B.Q Li, et al, Design of a Tea Garden Ant freezing Control System, in: PROCEEDINGS OF THE 2016 6TH INTERNATIONAL CONFERENCE ON MACHINERY, MATERIALS, ENVIRONMENT, BIOTECHNOLOGY AND COMPUTER (MMEBC), Tianjin, China, 2016, PP.736-738.

[7] B.Q Li, et al, Design of Electronic Compass, in: PROCEEDINGS OF THE 2016 6TH INTERNATIONAL CONFERENCE ON MACHINERY, MATERIALS, ENVIRONMENT, BIOTECHNOLOGY AND COMPUTER (MMEBC), Tianjin, China, 2016, PP.1240-1243.

[8] B.Q Li, et al, Research of Automatically Light-Adjusting Lamp, in: PROCEEDINGS OF THE 2016 INTERNATIONAL CONFERENCE ON COMPUTER ENGINEERING, INFORMATION SCIENCE \& APPLICATION TECHNOLOGY (ICCIA 2016), Guilin, China, 2016, PP.249-252.

[9] B.Q Li, et al, The Design and Realization of Fruit Harvesting Robot Based on IOT, in: PROCEEDINGS OF THE 2016 INTERNATIONAL CONFERENCE ON COMPUTER 
ENGINEERING,INFORMATION SCIENCE \& APPLICATION TECHNOLOGY (ICCIA 2016), Guilin, China, 2016, PP.261-264.

[10] B.Q Li, et al, A New Type of Automatic Opening and Closing Light-Operated Curtain, in: PROCEEDINGS OF THE 2016 INTERNATIONAL CONFERENCE ON MECHATRONICS ENGINEERING AND INFORMATION TECHNOLOGY(ICMEIT), Xian, China, 2016, PP.66-69.

[11] B.Q Li, et al, Design of the Intelligent Air Humidifier, in: PROCEEDINGS OF THE 2016 INTERNATIONAL CONFERENCE ON MECHATRONICS ENGINEERING AND INFORMATION TECHNOLOGY (ICMEIT), Xian, China, 2016, PP.201-203.

[12] B.Q Li, et al, The Design Implementation of the APP of Experiencing Guangxi Folk Custom, in: PROCEEDINGS OF THE 2016 INTERNATIONAL CONFERENCE ON ECONOMICS AND MANAGEMENT INNOVATIONS, Wuhan, China, 2016, PP.47-50.

[13] S.Y Zheng, et al, Digital Display Design of Ethnic Clothing of Nanling, in: PROCEEDINGS OF THE 4TH INTERNATIONAL CONFERENCE ON MECHATRONICS, MATERIALS. CHEMISTRY AND COMPUTER ENGINEERING 2015(ICMMCCE 2015), Xian, China, 2015, PP.2805-2808.

[14] S.Y Zheng, et al, Design and Implementation of Supermarket Personnel Management System Based On Java, in: PROCEEDINGS OF THE 2015 INTERNATIONAL CONFERENCE ON EDUCATION,MANAGEMENT AND COMPUTING TECHNOLOGY, Tianjin, China, 2015, PP.1724-1727.

[15] S.Y Zheng, et al, Analysis of Internet of Things Talent Training and Curriculum System Innovation, in: PROCEEDINGS OF THE 2016 INTERNATIONAL CONFERENCE ON EDUCATION,MANAGEMENT AND COMPUTING TECHNOLOGY(ICEMCT-16), Hangzhou, China, 2016, PP.957-960.

[16] S.Y Zheng, et al, Brief analysis on" HeYuanTong "Campus Mobile Phone APP Design, in: PROCEEDINGS OF THE 2015 5TH INTERNATIONAL CONFERENCE ON COMPUTER SCIENCES AND AUTOMATION ENGINEERING, Sanya, China, 2015, PP.151-154.

[17] S.Y Zheng, et al, Social Work in Teen Addiction Correction Services Research under the New Situation, in: PROCEEDINGS OF THE 2015 4TH NATIONAL CONFERENCE ON ELECTRICAL, ELECTRONICS AND COMPUTER ENGINEEERING (NCEECE 2015), Xian, China, 2015, PP.252-255. 